\title{
HENRY WHITEHEAD AND CHOLERA IN BROAD STREET
}

\author{
by \\ S. P. W. GHAVE, B.A. \\ Lecturer in Public Health \\ London School of Hygiene and Tropical Medicine
}

THE cholera epidemic in the St. James's district of Westminster in 1854 was perhaps the most terrible outbreak of that disease which this country has ever known-terrible because of its virulence and local concentration. More than five hundred people who lived or worked within an area only a few hundred yards square died of the disease in ten days. The outbreak is memorable, too, in the annals of epidemiology because of its association with John Snow's historic investigation into the Broad Street pump. Less well known, however, is the important contribution made by the Rev. Henry Whitehead, but it was, in fact, his work which constituted the first independent confirmation of Snow's hypothesis attributing the spread of cholera to contaminated water.

At the time of the epidemic, Whitehead, then aged twenty-nine, was serving his first curacy at St. Luke's, Berwick Street, the parish which included Broad Street and its environs. Throughout the dreadful days which followed the explosion of the outbreak on I September, the young curate worked incessantly to bring help and comfort to the afflicted and bereaved.

John Snow was busily engaged too, but in another way. His home in Sackville Street, Piccadilly, was little more than ten minutes walking distance from Berwick Street. Although he was already conducting an investigation into cholera in South London, he hastened to the scene of this new outburst. Having surveyed the local circumstances, his suspicions fell upon the 'much-frequented' pump in Broad Street. ${ }^{1}$ It appeared to him 'that there was no other circumstance or agent common to the circumscribed locality in which the sudden increase of cholera occurred'. He obtained the addresses of the eighty-nine fatal cases which occurred at the onset of the epidemic from the General Register Office and made detailed inquiries into each one. He reported, 'I found that nearly all the deaths had taken place within a short distance of the pump', and, further, he was able to establish that at least sixty-nine of these people had drunk water from it. On the evening of 7 September he put forward his views to a committee of the Board of Guardians, and although they were quite incredulous they ordered the pump-handle to be removed on the following morning.

The epidemic steadily declined, and when, by mid-September, the yellow flags which had given warning of the pestilence were removed from the streets, a newspaper correspondent entered the area and gave the following description of the aftermath of the visitation: ${ }^{2}$ 


\section{Henry Whitehead and Cholera in Broad Street}

The outbreak of cholera in the vicinity of Golden Square is now subsiding, but the passenger through the streets which compass that district will see many evidences of the alarming severity of the attack. Men and women in mourning are to be found in great numbers, and the chief topic of conversation is the recent epidemic. The shop windows are filled with placards relating to the subject. At every turn the instructions of the new Board of Health stare you in the face. In shop windows, on church and chapel doors, on dead walls, and at every available point appear parochial hand-bills directing the poor where to apply for gratuitous relief. An oil shop puts forth a large cask at its door, labelled in gigantic capitals 'Chloride of Lime'. The most remarkable evidence of all, however, and the most important, consists in the continual presence of lime in the roadways. The puddles are white and milky with it, the stones are smeared with it; great splashes of it lie about in the gutters, and the air is redolent with its strong and not very agreeable odour. The parish authorities have very wisely determined to wash all the streets of the tainted district with this powerful disinfectant; accordingly the purification takes place regularly every evening. The shopkeepers have dismal stories to tell-how they would hear in the evening that one of their neighbours whom they had been talking with in the morning had expired after a few hours of agony and torture. It has even been asserted that the number of corpses was so great that they were removed wholesale in dead-carts for want of sufficient hearses to convey them; but let us hope this is incorrect.

It was not long before stories of dire events which were said to have taken place in the cholera area became current. Many of these reports were exaggerated, and it was in part to provide a corrective that within a few weeks Henry Whitehead published his own account of the epidemic. Entitled The Cholera in Berwick Street, ${ }^{8}$ it provided a sober and objective report of the outbreak. Although the population of the area was literally decimated, there was, Whitehead said, 'no panic which somewhat surprised me, as I had always heard and read that great pestilences were invariably attended by wholesale demoralisation of the population'. He included in this report mortality figures, which he had compiled himself, for each street in the parish. This pamphlet is of interest in that no particular mention is made either of Broad Street or its pump. Berwick Street, not Broad Street, figured in the title because the parish church was situated there. As to the pump, the removal of the handle would seem to have passed unnoticed by the stricken population. That its waters were in any way connected with the cause of their distress was beyond belief, a view which was, in fact, expressed directly to Snow at the time. Whitehead, it would seem, either had not heard of it, or if he had, did not deem it worthy of mention.

In the period following the outbreak, John Snow was occupied in gathering further evidence in support of his thesis relating the spread of cholera to the waters of the Broad Street pump. At the same time, the Medical Committee of the General Board of Health carried out a local inquiry on behalf of the Government. This was conducted by three medical inspectors appointed for the purpose. In the course of the investigation, attention was paid to the account given by Whitehead, who is described as the 'exemplary and indefatigable curate of St. Luke's'. J John Snow also submitted his explanation of the outbreak, which was considered by the inspectors and rejected outright. 'After careful inquiry we see no reason to adopt this belief,' they concluded. 5

In reporting the results of this inquiry to Sir Benjamin Hall, the President 


\section{S. P. W. Chave}

of the General Board of Health, John Ayrton Paris, the chairman of the Medical Council, wrote: ${ }^{6}$

The extraordinary irruption of cholera in the Soho district which was carefully examined by Mr. Fraser, Mr. Hughes and Mr. Ludlow does not appear to afford any exception to generalisations respecting local states of uncleanliness, overcrowding, and imperfect ventilation. The suddenness of the outbreak, its immediate climax and short duration, all point to some atmospheric or other widely diffused agent still to be discovered, and forbid the assumption, in this instance, of any communication of the disease from person to person either by infection or by contamination of water with the excretions of the sick.

It was at this stage that, at the instigation of Dr. Edwin Lankester, the local Vestry took action on its own account. At a meeting held on 2 November 1854 , Lankester, who was later to become the first medical officer of health for the St. James's district, gave notice of the following motion:?

That a Committee of this Vestry be appointed for the purpose of investigating the causes arising out of the present sanitary conditions of the Parish of the late outbreak of cholera in the districts of Golden Square and Berwick Street.

At the next meeting, held three weeks later, there was some discussion before the motion was agreed to ${ }^{8}$ thereupon a committee consisting of nine vestrymen, including Lankester and the churchwardens, was appointed.

The inquiry had scarcely begun before it met with a serious set-back which almost brought the whole venture to an end. On I4 December 1854 the Vestry received a communication from the Board of Guardians of the Poor of St. James's, ${ }^{9}$ regretting the setting up of the inquiry

by reason of the expense that it is likely to entail upon the year's poor rate already wholly unequal to meet the ordinary expenditure, but in greater degree on account of the mischievous effects which a renewed investigation of the subject so recently made by the Government officers is calculated to inflict on the Householders and Inhabitants of the locality, now but slowly recovering from the serious depression of their trade and employment and by whom the inquiry instituted by Vestry is consequently viewed with feelings of dissatisfaction and alarm.

This gave rise to a motion that the Committee should discontinue its work which was only negatived 'after considerable discussion'.

Having thus been reprieved, the Committee began by considering all the available documentary evidence, and once again Henry Whitehead's first-hand account proved of value. It was decided that an approach be made to Sir Benjamin Hall to ask for such information concerning the local outbreak as might be available in his department. This request met with a blunt refusal on the grounds that investigations of this kind were more valuable when independent'.10 That this serious rebuff from the Government did not deter the Committee from continuing with its task may well have been due to the personality of Edwin Lankester. From his writings it is clear that he was not a man who would lightly have abandoned a chosen course of action. His characteristic persistence and doggedness are outstanding features of the series 


\section{Henry Whitehead and Cholera in Broad Street}

of annual reports which he made to the Vestry during his long tenure of office as medical officer of health.

Whether as a result of the leadership of Lankester or not, the Committee of Inquiry went on with their work. They next set out to obtain the information they needed by circulating a questionnaire to the householders of the district, asking a number of details of their living circumstances. It was not long before they learnt that this is not often a fruitful method of inquiry. 'This measure did not produce the anticipated results,' they reported.11 The Committee, therefore, decided to seek this information by means of personal interviews, and to this end they added eight new members to their number. Among these new-comers were John Snow and Henry Whitehead, who now probably met for the first time. Snow had just completed his book On Cholera, which was published in January 1855 , and he presented a copy to Whitehead. But, having read it, the young curate remained unconvinced. He wrote to Snow setting out his reasons and stating that, in his opinion, an intensive inquiry would reveal the falsity of the argument attributing the spread of cholera to the Broad Street pump.

Whitehead thereupon determined to carry out such an inquiry himself with the aim either of confirming or refuting the 'Snovian' hypothesis. The investigation which he carried out in the ensuing months in Broad Street was embodied in a report entitled 'Special Investigation of Broad Street', ${ }^{12}$ which he submitted to the Committee in June 1855 . When printed subsequently this report covered forty-two printed pages. It is a record of a thorough and searching investigation carried out with all the objectivity of a truly scientific inquiry.

Whitehead set out to interview every family which had been resident in Broad Street at the time of the outbreak. A number of these had moved away, but he endeavoured to communicate with them, in some cases travelling 'a considerable distance to do so'. In the case of the residents who remained in Broad Street, Whitehead went over the ground many times, often visiting a family on four or five occasions in order to obtain and confirm the facts that he needed. In respect of every person who had died from cholera he ascertained the name, age, position of the rooms occupied, the sanitary arrangements, the water drunk, with particular regard to the pump, and finally the hour of onset of the fatal attack. He found that the piped water supplied to the district by the two private water companies could be excluded as a factor in the spread of cholera, and confirmed that the only other source of water in common use was the pump.

'Slowly and I may add reluctantly,' reported Whitehead, the conclusion was reached 'that the use of this water was connected with the commencement and continuance of the outburst'. The steps by which he came round to this view are recounted by him in detail. Of the fifty-six fatal cases among the residents which occurred between 31 August and 2 September, only two were not shown to have drunk the pump water. Among the twenty-eight non-residents who died of cholera, twenty-four worked in factories where water from the pump was in constant use.

Whitehead sought the fifty residents who had contracted cholera but had 


\section{S. P. W. Chave}

recovered. He discovered that, of these, thirty-five had consumed the pump water after 30 August, and that thirty-four were seized during the period 31 August to 2 September. Throughout the investigation Whitehead took account of the residents who had not been attacked. He ascertained that 279 of these had not consumed the water from the pump between the last week of August and the first week of September, but that a further forty-three had, in fact, done so. Altogether Whitehead was able to contact personally no less than 497 of the 896 persons who were resident at the time of the outburst. He remarked that he was able to do this because he had collected 'full statistical information throughout the whole of St. Luke's district', and was thus dealing with a matter with which he was already fully familiar.

The ordinary course of my duties taking me almost daily into the street, I was under no necessity to be either hasty or intrusive, but asked my questions just when and where opportunity occurred, making a point of letting scarcely a day pass without acquiring some information and not caring how often $I$ had to verify it in quarters where I could rely upon a willingness to converse upon the subject.

He concluded that among those who drank the pump water, the ratio of persons attacked to those unaffected was $80: 57$, whilst the corresponding ratio among the non-drinkers was $20: 279$. Clearly the case against the pump was a strong one.

Whitehead then went on to add what might be described as a clinical study to his statistical inquiry. He gave a detailed description of the occurrence of cholera in fifteen households, in every case of which the evidence clearly implicated the pump. Among these examples Whitehead paid particular attention to the case which Snow had cited as an especially noteworthy piece of evidence in favour of his hypothesis. This concerned the widow of Hampstead. This good lady had a bottle of water from the Broad Street pump delivered to her home each day by a cart which travelled from Soho. She contracted cholera on I September and died the next day. A niece from Islington, who visited the old lady and partook of the water also died. No other cases of cholera occurred in the districts in which these women lived. It would appear that some people had expressed the view that the water-bottle had not been filled at the Broad Street pump. Whitehead sought out her sons and confirmed that they themselves had filled the bottle at the fatal pump. Neither Snow nor Whitehead revealed the lady's identity, but she was, in fact, Susannah, the widow of one Eley, who had owned the percussion-cap factory at 38 Broad Street.

The young curate then went on to give a detailed account of several individual cases of cholera 'as an illustration of the manner in which the whole inquiry had been conducted, and as showing very remarkably, the utter worthlessness of hastily collected facts'.

In presenting his findings, Whitehead paid particular attention to instances which appeared to refute Snow's hypothesis, namely, to examples of people who drank the pump water without ill-effect and to others who were stricken without having consumed the suspected water. Concerning the latter, in several 


\section{Henry Whitehead and Cholera in Broad Street}

instances, persistent inquiry led to the suspicion that the water had, in fact, been consumed. There were also several cases of cholera having been contracted by persons who had been in close attendance upon other sufferers.

Whitehead also discovered that the houses which escaped the disease altogether were those which accommodated considerably fewer than the average number of residents in the houses in the street. These dwellings were found in other respects to be 'the best regulated in respect of their water systems and therefore there was less need for the inmates to resort elsewhere for their water'. Moreover, there were fewer children in these houses, the children were 'the general carriers of the pump water wherever it was habitually used'. This accounted for the relative immunity of the aged and infirm, for they had no one to fetch water for them.

In taking account of the official view that the spread of cholera was in some way connected with the effluvia rising from the drains, Whitehead established that the inhabitants of cellars and kitchens, where the effects of these exhalations were likely to have been most pronounced, had, in fact, suffered less than those living on upper floors. Three women living in kitchens who had died during the epidemic were shown to have washed the linen of cholera patients.

On the assumption that the pump water had contained the cause of the infection, Whitehead attempted to determine the period during which the choleraic agent had been present. He found that he could not assign any cases of cholera to the consumption of pump water after 8 a.m. on 6 September. Referring back to the statistics quoted in his first pamphlet, he noted 'supposing the number of rapid cases assigned to each day may be taken as an index to the malignancy of the cause, ... there was then a very perceptible decrease ... after the cause had been in operation somewhat over forty-eight hours'. The day of greatest pollution was $3 \mathrm{I}$ August, and he concluded that partial purification must have occurred by 3 September; he mentioned that he himself had drunk a little of the water with some brandy on that day. But in regard to this he uttered a timely warning, 'I trust that no-one will be for settling these questions by single instances'.

What is perhaps the most interesting part of Whitehead's investigation was his discovery of the way in which the well-water became polluted. 'The possibility of the water having been contaminated by matter thrown off from a cholera patient, who might, so to speak, have imported the disease from another locality had often been discussed in committee,' but no evidence was forthcoming to support this contention. Whitehead made this discovery after he had reached the end of his inquiry and prepared his report. In a typically modest understatement, the young curate wrote: ${ }^{13}$

One day last week, however, I happened to be studying the Registrar's Returns (of deaths) for a purpose unconnected with this matter, when my eye fell upon the following entry:

'At 40, Broad Street, 2nd September, a daughter, aged five months, exhaustion after an attack of Diarrhoea four days previous to death.'

He had, in fact, known of this case much earlier, but had passed it over 


\section{S. P. W. Chave}

because it concerned an infant. It was only now that he appreciated its possible double significance; first it had occurred in the house nearest the pump, and secondly the child's attack antedated the violent outbreak by about forty-eight hours.

He was that day (3 April I855) about to present his report to the Committee. Before doing so, he hastened to the house and interviewed the dead child's mother. The poor woman lived in the back room on the ground floor of No. 40, and had lost both her child and her husband, a policeman, in the late epidemic. In answer to Whitehead's questions, she described how, during her baby's illness, she had steeped its soiled napkins in pails of water and had emptied some of these into the cesspool at the front of the house. The account continued: 'Being struck by the dangerous proximity of the cesspool to the pump well, I lost no time in communicating the facts to the Committee who ordered an inspection of the well to be made forthwith.' This examination was carried out by Jehosephat York, the Surveyor, and revealed beyond all doubt the seepage of faecal matter through the decayed brickwork of the cesspool to the well which was less than three feet away. ${ }^{14}$

Some time later Whitehead interviewed Dr. Rogers, who had attended the young child. Rogers had not kept his case notes, but expressed the view that the cause of death was acute diarrhoea and not cholera, an opinion he subsequently repeated at a meeting of the Epidemiological Society. Nevertheless, there is a strong probability that Whitehead had succeeded in discovering the primary source of the terrible outbreak.

John Snow the doctor, and Henry Whitehead the curate, submitted their reports separately. The Committee noted ${ }^{15}$ that

It was Dr. Snow who first endeavoured to trace out a relation . . . he supposed might exist between the use of this well-water and the cholera outbreak. The result of his laborious inquiry was in favour of that supposition. Mr. Whitehead entertaining, at first, adverse views ended his special investigation of Broad Street by a remarkable confirmation of Dr. Snow's numerical results.

In the light of this imposing body of evidence, and without necessarily accepting Snow's hypothesis regarding the cause of cholera, the Committee reached the unanimous conclusion that 'the sudden severe and concentrated outbreak beginning on August 3 ist and lasting for the few early days in September was in some manner attributable to the use of the impure water of the well in Broad Street'. ${ }^{16}$

On 9 August 1855 Lankester presented the Committee's Report to the Vestry. ${ }^{17}$ The Minutes record that he spoke 'at considerable length and read a portion as well as stated the general character and contents of the same'. There followed a discussion and 'the question being put, and the number for and against found to be equal, the Chairman gave the Casting Vote in favour thereof'. It was only by this narrow margin that this important document came to be published. It consisted of $\mathrm{I} 75$ pages and included the individual reports submitted by Snow, Whitehead and York the surveyor, as well as an account 


\section{Henry Whitehead and Cholera in Broad Street}

of the work and findings of the Committee. Despite a protest by the Board of Guardians against its publication on the grounds of expense, 500 copies of the report were printed. Some of these were circulated to other parochial bodies, and it was hoped that the costs would be met through sales to interested members of the public. In this the Committee were disappointed, and in April $185^{18}$ the Vestry requested the sum of $£$ I 70 I $2 s .7 d$. from the Poor Rate to cover the cost of the inquiry.

The Report of the Committee of Inquiry and John Snow's book On Cholera were reviewed in the Lancet together, ${ }^{19}$ the one being regarded as complementary to the other. Particular attention was given to 'Mr. Whitehead's searching inquiry', which established 'that but for this source of water supply (i.e. the Broad Street pump), the deaths from cholera instead of amounting to seven hundred cases would not have reached fifty'. The writer concluded: 'The evidence is so elaborate that we must refer the reader to the work itself for the details.'

It would appear that, for a time at least, it was not unusual for Whitehead's name to be linked with that of Snow when reference was made to the Soho epidemic. For example, at a meeting of the Epidemiological Society in June $1855,{ }^{20}$ at which Snow read a paper on cholera, one of the speakers remarked during the ensuing discussion that the cause of the outbreak in Soho 'had been entirely explained by the labours of Dr. Snow and the Rev. Mr. Whitehead, a curate of the district'.

Later, in $187 \mathrm{I}$, J. Netten Radcliffe, the first permanent inspector on the staff of the Medical Department of the Privy Council, writing of the transmission of cholera through polluted water, said:

This doctrine now fully accepted in medicine, was originally advanced by the late Dr. Snow; but to Mr. Whitehead unquestionably belongs the honour of having first shown with anything approaching conclusiveness the high degree of probability attaching to it. Only now perhaps can the great public importance of the doctrine be clearly appreciated, and the value of Mr. Whitehead's inquiry properly estimated. ${ }^{21}$

It might perhaps be of interest at this point to inquire into the antecedents of this exceptional young clergyman. The details of his career are to be found in the memorial sketch written shortly after his death by his friend Canon Rawnsley. ${ }^{22}$ Henry Whitehead was born on 22 September 1825 in Ramsgate, Kent, at Chatham House, a small public school where his father was master. He was the eighth of ten children, and grew up in the school, becoming in due course a pupil and, later, an assistant master. For twenty-two years Henry lived in the atmosphere of school with his father, Thomas, in the inseparable roles of parent and teacher. Thomas Whitehead is said to have been 'a disciplinarian of the old type'; in school he was 'stern and uncompromising', but outside the classroom he was 'tender and kind'. The curriculum at Chatham House was a liberal one for those days, for, although it was based largely on the classics, it included among other things a weekly lecture on the sciences.

Henry was a promising pupil; from an early age he showed marked ability in 


\section{S. P. W. Chave}

English composition, and at twelve years was the top of his class in Latin and Mathematics. It may be, therefore, that his later capacity for painstaking inquiry and his accuracy of detail sprang from the demands of his classical and mathematical studies conducted for so long in the scholastic environment of his home.

In 1847 , having served for three years on the teaching staff under his father, Henry went up to Lincoln College, Oxford. It was while he was at the University that he made up his mind to enter the Church, and, having obtained his B.A. in 1850, he left to seek ordination. In those days titles were fewer than applicants, and he considered himself fortunate when he was offered a post as assistant curate at $£$ Ioo per annum by the Vicar of St. Luke's, Soho. In I851, following his ordination as a deacon, he took up his duties among the residents of the crowded slums of the Berwick Street area. By the time the cholera broke out, three years later, he was a welcome visitor in the homes of his parishioners, a fact which proved of great value to him during the four months of his painstaking inquiry.

Whitehead continued his ministry at St. Luke's for two years after the epidemic before he left to seek another curacy. In the years that followed he served in several London parishes, where, apart from his ordinary duties, he took a practical interest in many of the social problems of the day, notably in juvenile delinquency. ${ }^{28}$ Then, in 1865 , the threat of cholera returned again to this country. Several small outbreaks occurred which gave rise to apprehension and foreboding in the mind of the public.

By that time John Snow was dead, and there were still many sceptics of his theory concerning the transmission of cholera by polluted water. (Writing in 1858 , John 'Simon had referred to Snow's 'peculiar doctrine as to the contagiousness of cholera'.) Whitehead, therefore, considered the moment appropriate to publish his own account of the Soho outbreak, principally to sound a warning of the dangers which might arise through neglect of the lessons that it provided.

In his first article published in Macmillan's Magazine, ${ }^{24}$ he described his investigation in Broad Street, and gave some interesting sidelights which had not been included in the earlier reports. The following passage is characteristic of his clear prose description:

.. limited in its extent, brief in its duration, and continually on the wane from the first moment of its appearance was this great outbreak, the like of which had perhaps never before been seen in this country . . . as soon as it began to subside leaving us time for reflection and discussion, we indulged in speculation regarding its origin; but none of us could advance a satisfactory hypothesis, for the simple reason that its facts seemed to contradict all the then prevalent theories concerning the spread of cholera.

Want of cleanliness, insanitary conditions and intemperance were examined and rejected. There was satisfaction at the initiation of the inquiry by the Vestry of St. James, although there were some vestrymen who deprecated this step as being 'detrimental to the reputation of the Parish'. But the majority persisted in the intention to establish the cause if it could be found. In the inquiry 


\section{Henry Whitehead and Cholera in Broad Street}

Every local condition of the infected district, such as elevation of site, nature of soil and subsoil, surface and ground plan, streets and courts, density and character of population, internal economy of houses, cess-pools, house-drains, and sewage was minutely investigated. But though we found much to lament or condemn in most of these particulars, we could not find in them any satisfactory explanation of the sharp line of demarcation which on every side surrounded what we called the 'cholera area'. [He described how John Snow, suspecting the water in the well, had secured the removal of the pump handle.] But scarcely anyone seriously believed in his theory.

He mentioned his own adverse reaction to Snow's hypothesis, and then went on to describe the local investigation.

In the face of these objections the evidence implicating the pump kept on accumulating not only in my hands but also in those of the other members of the committee ... until at length sufficient evidence was collected to bring the whole committee to the unanimous verdict which they finally recorded.

\section{He mentioned that}

from St. Luke's pulpit on September 8th I congratulated the poor old women who formed a considerable proportion of the congregation upon their remarkable immunity from the pestilence. At that time I had been too busy to meddle with hypotheses and had not even heard of Dr. Snow's bill of indictment against the pump. The escape of these women, many of whom, living alone, had no-one to send to the well, was one of those 'eccentricities' which found their best explanation in the pump theory.

One of the strongest facts in connection with this inquiry is that the impurity of the wellwater was, in point of time, the very last discovery made by the investigation. We collected the evidence already described, not only in ignorance of the fact of the well having been contaminated, but in the face of positive and seemingly reliable evidence to the contrary. The sides of the well had been examined and declared in a report made by order of the Paving Board on November 24th, 1854 , 'to be free from any fissures or other communication with drains or sewers by which such matters could possibly be conveyed into the waters'. Both chemical and microscopical analyses had 'failed to detect anything which could be pronounced peculiar to the cholera period or capable of acting as a predisposing co-operating or specific agent in the production of that disease'. We stand exonerated from the imputation of seeking to impugn the well-water on the ground of any previous knowledge of its impurity. Indeed for my own part I had a leaning the other way.

After giving a description of the well as revealed by the surveyor's inspection, he went on to call for an end of the surface wells in London. 'Yet strange to say they are held in great repute.'

He gave details of the circumstances of the fatal cases in No. $4^{\circ}$ Broad Street, and remarked, 'There was some discussion among the doctors on whether the child did actually have cholera, its own doctor claiming that it did not. The circumstantial evidence is, however, very strong that it was in this way that the epidemic was caused.' Referring to the Report to the Vestry, he said, 'If it could have been widely circulated it would have rendered it wholly unnecessary for me to write another line on the matter to which it relates.'

Several months later he published a second article in the same magazine ${ }^{25}$ entitled 'The Influence of Impure Water on the Spread of Cholera'. In this he drew attention to the continuing prevalence of cesspools and to the widespread use of shallow wells. He mentioned how difficult it was to convince people of 


\section{S. P. W. Chave}

the dangerous condition of such waters when their taste and appearance continued to be satisfactory. Once again he gave the salient details of the Soho epidemic and the manner of its causation. He expressed the hope that what he had written would 'moderate some of the terrifying notions which prevail concerning the causes of cholera'.

Rawnsley ${ }^{26}$ tells us that the publication of these articles by Whitehead led to the offer of a post by the editor of the Daily Newes, who is said to have remarked, 'Is there no small bishopric for such a man?' The offer was, of course, not accepted.

Two weeks after the appearance of the second article in July I866, the disaster of which Whitehead had given forewarning occurred. Cholera broke out in the crowded slums of East London and spread through the very circumstances that he had feared. It was the contaminated water of the River Lee, supplied untreated by the East London Water Company, which carried the disease into thousands of homes in the localities around the docks.

The Bishop of London called for volunteers to help in the stricken area, from among the clergy who had had previous experience of cholera. Whitehead immediately offered his services, but his vicar objected on the grounds of the risk to the curate's wife and her newly born child. Whitehead insisted that his knowledge and experience were needed, whereat the vicar required him to provide a substitute out of his own slender stipend and also forbade him to return to his home so long as the epidemic lasted. Whitehead submitted to these conditions and went to the aid of the rector of Bethnal Green in the heart of the epidemic area. In the course of his work there he met Netten Radcliffe, who had been sent by Dr. Simon to investigate the circumstances of the outbreak. The two men became good friends, and Whitehead gave Radcliffe considerable help in his inquiries which led to the tracking down of the outbreak to its source. In his report ${ }^{27}$ Radcliffe made a handsome acknowledgement for this assistance:

In carrying out this investigation concerning the earliest cases I had the good fortune to be assisted by the Rev. H. Whitehead, M.A., to whom Medicine is in a great measure indebted for that elaborate investigation of the cholera outbreak in the parish of St. James, Westminster (the Broad Street pump outbreak) which it is now known gives Dr. Snow's opinion of its origin a probability practically amounting to a demonstration.

When on a later occasion Radcliffe publicly acknowledged his indebtedness to Whitehead, the latter modestly discounted the value of his contribution, saying: ${ }^{28}$

He has been good enough to say that I rendered him some assistance on this occasion, but the only assistance he needed was of a kind very easily given, namely, the support of my arm whilst he limped about the banks of the Lee still suffering from the effects of rheumatic fever.... I have only to add respecting this epidemic that Mr. Radcliffe's inquiry into its causes resulted in further confirmation of Dr. Snow's doctrine on the mode of propagation of cholera.

With the decline of the East London outbreak, Whitehead returned to his duties in Highgate. In May 1867 he read a paper's entitled 'Remarks on the 


\section{Henry Whitehead and Cholera in Broad Street}

Outbreak of Cholera in Broad Street, Golden Square, London, in 1854' to the Epidemiological Society of London, of which Radcliffe was then the Honorary Secretary. This paper is of interest in that Whitehead set out to scotch a rumour that has in fact persisted down to the present day. This was that the closure of the Broad Street pump at John Snow's instigation was responsible for bringing the cholera epidemic to an end. Snow himself never made such a claim, nor had any of the formal inquiries made any comment on the consequences of the removal of the pump-handle. It is possible that this idea originated locally, following the publication of the Vestry's Report incriminating the pump. But it is Benjamin Ward Richardson who was largely responsible for giving a seemingly authoritative support to this myth. Four years after the Broad Street episode, John Snow died suddenly, and Richardson wrote a memoir of his late friend in which he gave his own version of Snow's intervention at the Board of Guardians on the night of 7 September $1854:{ }^{30}$

When the Vestry men were in solemn deliberation they were called to consider a new suggestion. A stranger had asked in a modest speech, for a brief hearing. Dr. Snow, the stranger, was admitted, and in a few words explained his view of the 'head and front of the offending'. He had fixed his attention on the Broad Street pump as the source and centre of the calamity. He advised the removal of the pump handle as the grand prescription. The Vestry was incredulous but had the good sense to carry out the advice. The pump handle was removed and the plague was stayed. There arose, hereupon, much discussion among the learned . . . but it matters little for the plague was stayed.

In this way the story was sent on its way to a wider audience. It received further reinforcement in 1866, from the pen of Edwin Lankester, who in that year published his version of the Soho epidemic. ${ }^{31}$ In referring to the incident of the pump handle he remarked:

The Board of Guardians met to consult as to what ought to be done. Of that meeting the late Dr. Snow demanded an audience. He was admitted and gave it as his opinion that the pump in Broad Street, and that pump alone, was the cause of all the pestilence. He was not believed-not a member of his own profession, not an individual in the parish believed that Snow was right. But the pump was closed nevertheless and the plague was stayed.

Whitehead, who knew the details of the outbreak better than anyone living, was at pains to show that there were no grounds for making such a claim. He began:

It is commonly supposed and sometimes asserted even at meetings of Medical Societies that the Broad Street outbreak of cholera in 1854 was arrested in mid-career by the closing of the pump in that street. That this is a mistake is sufficiently shown by the following table which, though incomplete, proves that the outbreak had already reached its climax, and had been steadily on the decline for several days before the pump-handle was removed.

The table revealed the daily toll of the epidemic and showed how the number of fatal attacks had diminished from 142 on I September to 14 on 8 September, the day on which the pump was closed. Thereafter it fell to single figures and slowly dwindled away. This table included only residents, and excluded the 


\section{S. P. W. Chave}

non-resident work-people who had contracted cholera in the first days and died outside the district.

Whitehead added:

The table, if more complete, would have indicated more clearly even than it does now, the exceeding virulence of the outbreak during its two or three earlier days, and the rapidity of its decline after the climax was passed; and the column of fatal attacks, incomplete as it is, establishes the fact that the climax was reached within a very few hours of the first manifestation of the outbreak. Clearly the original cause of the explosion must very soon have lost much of its fatal power.

This rebuttal of the rumour did not succeed in its purpose. The story of the pump handle, like that of King Alfred and the cakes, was one which caught the popular imagination and was not to be disposed of lightly.

In 1955 the centenary of the publication of John Snow's book On Cholera was commemorated by the Epidemiological Section of the Royal Society of Medicine-the direct successor of the Epidemiological Society of London. Professor Bradford Hill, the President of the Section, in his address on that occasion, discussed the question of the pump handle yet again, and repeated the substance of the remarks made by Whitehead many years before: ${ }^{32}$

Though conceivably there might have been a second peak in the curve, and though almost certainly some more deaths would have occurred if the pump-handle had remained in situ, it is clear that the end of the epidemic was not dramatically determined by its removal. The deaths had already been declining from a marked peak for at least five days.

He added that Snow recognized this and had 'never occupied the flimsy pedestal upon which some would place him'.

This does not in any way detract from the value of Snow's researches, nor does it throw doubt on his conclusions, which are based on more substantial, though less dramatic, evidence than that afforded by the removal of the handle from the Broad Street pump.

But, to return to 1867 , Whitehead, in his address, revealed one important result of the closure of the pump which had not previously been suspected, and which seems subsequently to have been overlooked. He said:

I must not omit to mention that if the removal of the pump-handle had nothing to do with checking the outbreak which had already run its course, it had probably everything to do with preventing a new outbreak, for the father of the infant, who slept in the same kitchen, was attacked with cholera on the very day (September 8th) on which the pump-handle was removed. There can be no doubt that his discharges found their way into the cess-pool and thence to the well. But, thanks to Dr. Snow, the handle was then gone.

Whitehead pointed out that the evidence indicated that the water from the well was not injurious before 30 August, nor for long after 2 September. It was not to be wondered that the well purified itself, since (i) the pollution caused by the infant's discharges ceased on 30 August, (ii) the body of water held in the well was not great, and (iii) consumption of water was exceptionally high during 


\section{Henry Whitehead and Cholera in Broad Street}

the early days of the outbreak-some cholera patients drank as much as seventeen pints in a day.

Concluding, Whitehead remarked:

The slackened rate of decline after September 3 rd. does not, in the present state of knowledge upon the mode of propagation of cholera, need any explanation. I now only wonder that with such a start from the agency of the pump, and with so much material thus supplied for the continuance of the outbreak by other means of communication it had so little power to sustain itself for any length of time after its original promoter had begun to suspend its fatal operation.

This paper, presented by a parish clergyman to an audience of epidemiologists, is interesting not only for its content but also for the lucid presentation of the data and for the cautious manner in which the conclusions were drawn. It was subsequently published in the Transactions of the Society.

Whitehead's experiences in the East End of London had aroused his interest and concern for the manifold problems of the residents of this area, and, as a result, in the year following the epidemic, he took up a curacy in Stepney. His two years there were followed by a short spell of service in Hammersmith, after which he returned to dockland as the Vicar of St. John's, Limehouse. Writing of Whitehead's ministry among the people of this neglected area, Rawnsley ${ }^{38}$ says that he was 'working not only as their parish priest, but as the high priest of sanitation and order'. At the end of three years of unremitting toil among the dockworkers at a time of economic slump, he was offered the benefice of Brampton, a small town in Cumberland by the patron, the Earl of Carlisle, and after much deliberation he decided to accept.

In the course of the twenty-three years which he had served first as assistant curate and later as vicar in seven districts of London, Whitehead had built up a wide circle of acquaintances in many walks of life. Before he left the busy streets of the East End to start a new life as vicar of a quiet country town, these friends combined to present him with a loving cup as a parting gift. The presentation was made at a dinner held in the 'Rainbow' tavern in Fleet Street on 16 January 1874 . This occasion was rendered noteworthy in that Whitehead delivered what is said to have been the longest after-dinner speech on record. Many years later a writer in The Times gave the following account of the event: ${ }^{34}$

It is a remarkable instance of the way in which character, without any adventitious aids, can impress men, that on the eve of his leaving London, he was entertained at dinner by a body of men, many of them distinguished in their various callings and all of them attracted by the mere personality of the man. It is a proof of his originality and humour that in returning thanks for the toast of his health he was able to fix the attention and sustain the interest of his hearers for three hours on 'Twenty years as a London curate'-probably the longest afterdinner speech on record. Few survivors of the gathering will ever forget the sustained fascination of that speech.

In the course of this address, ${ }^{35}$ Whitehead referred to the two cholera outbreaks with which he had been concerned. He gave the following personal reminiscence of John Snow, probably the only one we have from a source other than B. W. Richardson's memoir: 


\section{S. P. W. Chave}

Yet for wholly exceptional reasons, I may say a few words about Dr. John Snow-as great a benefactor in my opinion to the human race as has appeared in the present century. Dr. Snow had long believed that he had discovered the mode in which cholera is propagated and fortunately he was at hand to direct an inquiry into the cause of the Broad Street outbreak, which inquiry resulted in a remarkable confirmation of his hypothesis. The story of his researches and of this investigation in particular I have elsewhere related at some length and therefore I will not now go into the subject. What I chiefly wish to dwell upon is the calm prophetic way in which he would talk of the ultimate results of the doctrine which he laid down.

'You and I', he would say to me, 'may not live to see the day, and my name may be forgotten when it comes, but the time will arrive when great outbreaks of cholera will be things of the past; and it is the knowledge of the way in which the disease is propagated which will cause them to disappear.'

He died in 1858 and since his death we have seen a complete revolution in the mode of investigating the causes of cholera and typhoid, a revolution already fruitful in beneficial consequences and destined hereafter to achieve all the important results that he anticipated. He did not in his lifetime receive all the recognition which was due to his genius, though unstinted respect was paid to his character.

'Dr. Snow's views on cholera', said a medical friend to me in 1855 , 'are generally regarded in the profession as very unsound.' 'If that be the case', I replied, 'heresy may be as good a thing in your profession as some of you are apt to suppose in mine.'

A portrait of Dr. Snow hangs on my study wall and ever serves to remind me that in any profession the highest order of work is achieved not by fussy demand for 'something to be done' but by patient study of the eternal laws.

It is of interest to note that the comment on John Snow's character is one which was generally made and appears on his tombstone. ${ }^{36}$ Whitehead's remarkable speech to his friends was taken down verbatim by a shorthand writer and was published later under the title of Experience of a London Curate.

In March 1874 he began his ministry in Cumberland and remained there for the rest of his life. So far as is known he never again concerned himself with cholera-the Cumberland fells were far removed from the unhealthy slums of Soho and dockland. As vicar, Whitehead played a leading part in local affairs, particularly in regard to the schools, clubs and friendly societies of the town. It was typical of the man that when on one occasion he was in dispute with the Education Department about school accommodation in Brampton, he made a personal census of the children of school age in the area, and showed the inaccuracy of the 'estimate' made by the officials of the department. ${ }^{37}$

In later life he became interested in historical and archaeological subjects, and he wrote a number of articles on the registers, the bells and the plate of the churches in the diocese of Carlisle. These display the same keen sense of observation and concern for accuracy of detail which were so marked in his cholera studies.

On 5 March 1896 , at the age of seventy, he died suddenly at Lanercost Priory, and was buried in the churchyard at Brampton. He left a widow and two unmarried daughters.

The memory of Henry Whitehead is kept to this day in Brampton. In 1956, the sixtieth anniversary of his death was marked by a public lecture given by the present incumbent, the Rev. K. Harper, in which he touched upon many 


\section{Henry Whitehead and Cholera in Broad Street}

aspects of the life of this singular parson. ${ }^{38}$ In the same year, too, the headstone on Whitehead's grave which had fallen into disrepair was restored by the local congregation.

Henry Whitehead is remembered as a devoted pastor and as an enlightened worker for social improvement. But his endeavours in the epidemiological field were by no means negligible. The value of his work on cholera in no way detracts from that of John Snow, rather it is complementary to it. To Snow undoubtedly belongs the credit for having first elucidated the means whereby cholera is spread. In his lifetime his discovery was received with incredulity by the majority of the medical profession who were satisfied that the transmission of this and other epidemic diseases could be explained in terms of miasmata. Whitehead, entering into this controversy almost by chance, had no reason to doubt the truth of the prevailing doctrine. Snow's indictment of the Broad Street pump seemed at the outset as unsatisfactory to him as it did to the medical inspectors of the Board of Health. It is, therefore, greatly to his credit that when the opportunity presented itself, he was not content to leave the issue undetermined. For him it was not sufficient to seek to refute Snow's explanation by argument, but by demonstration. This he set out to do, and, in the event, his research constituted a remarkable confirmation of the hypothesis he had anticipated that it would refute. His discovery of the manner in which the well had become contaminated provided the final link in the chain of evidence which put the issue beyond reasonable doubt. It should not be forgotten that, but for Whitehead's work, Snow's explanation of the Soho epidemic would have remained presumptive.

Although without special training or knowledge in medical matters, Whitehead displayed the keen observation, the strict regard for objectivity and measurement and the ability to evaluate evidence which are the hall-marks of sound scientific inquiry. His studies, together with those of John Snow, provide an outstanding example of the fruitful combination of the intelligent layman and the medical specialist.

Whitehead's work served both to confirm and underline the thesis that cholera is a water-borne disease, which, with his persistent efforts to bring this knowledge into practical use, made a signal contribution to the advancement of public health.

\section{ACKNOWLEDGEMENTS}

My thanks are due to Professor J. M. Mackintosh and Professor W. S. Walton for their encouragement and advice, to the Archivists of the London County Council and the City of Westminster for their valuable assistance, and to Miss J. Cooper for her help in preparing the paper for publication.

\section{REFERENCES}

I. Snow, J. (1855), On the Mode of Communication of Cholera, 2nd ed., London, pp. 38-40.

2. The Times, 15 September 1854 , London, p. 9. 


\section{S. P. W. Chave}

3. WhiteheAd, H. (1854), The Cholera in Berwick Street, London.

4. General Board of Health, Report of the Committee for Scientific Inquiries in relation to the Cholera Epidemic of 1854, London, Appendix, p. 158.

5. Ibid., p. 52.

6. General Board of Health (1855), Report of the Medical Council to the Rt. Hon. Sir Benjamin Hall in relation to the Cholera Epidemic of 1854 , London, p. 7.

7. Vestry of St. James's Westminster, Minutes, 2 November 1854 (MSS. Westminster City Archives).

8. Ibid., 23 November 1854 .

9. Ibid., 14 December 1854 .

io. Vestry of St. James's Westminster, Report on the Cholera Outbreak by the I1. Ibid. Cholera Inquiry Committee (1855), London, p. v.

12. Ibid., Mr. Whitehead's Report, pp. 121-69.

13. Ibid., p. 159 .

14. Ibid., Mr. York's Report, pp. 170-4.

15. Ibid., p. 76.

16. Ibid., p. 83 .

17. Vestry of St. James's Westminster, Minutes, 9 August 1855.

18. Board of Guardians of St. James's Westminster, Minutes, 4 April 1866 (London County County Archives).

19. Lancet (1855), London, II, 524 .

20. Lancet (1855), London, II, II.

21. Rawnsley, H. D. (1898), Henry Whitehead-A Memorial Sketch, Glasgow, p. 40.

22. Ibid., pp. 1-48.

23. Whitehead, H., The Times, London, 26 December 1855, p. 9.

24. Whitehe Ad, H. (December 1865), 'The Broad Street Pump: An Episode in the Cholera Epidemic of 1854', Macmillan's Magazine, Cambridge, p. I 13.

25. Whit в He AD, H. (July I866), 'The Influence of Impure Water on the Spread of Cholera', Macmillan's Magazine, Cambridge, p. 182.

26. RAWNSLEY, H. D., vide supra, p. 4I.

27. Privy Gouncil, Ninth Report of the Medical Officer, for 1866. Appendix No. 7. Report by Mr. J. Netten Radcliffe on Cholera in London and especially the Eastern Districts, p. 288.

28. Whit e he AD, H. (1874), Experience of a London Curate, Clapham.

29. WhiteheAD, H. (1867), 'Remarks on the Cholera Outbreak in Broad Street, Golden Square, London, in 1854', Trans. Epid. Soc. of London, m, 99-105.

30. Snow, J. (1858), On Chloroform and Other Anaesthetics-with a memoir of the author by Benjamin W. Richardson, London.

31. Lankester, E. (1866), Cholera, What it is and How to Prevent It, London, p. 34.

32. Hill, A. Brad ford (1956), 'Snow-An Appreciation', Proc. Roy. Soc. Med., xivmi, 1010.

33. RAWNSLEY, H. D. (1898), vide supra, p. 82.

34. The Times, 9 March 1896 , p. 6.

35. WhiteheAD, H. (1874), Experience of a London Curate.

36. Grave, S. P. W. (1955), Fohn Snow and Cholera in London, London School of Hygiene, p. 84 .

37. RAWNSLEY, H. D. (1898), vide supra, p. I14.

38. Har per, Rev. K., personal communication, 1956. 


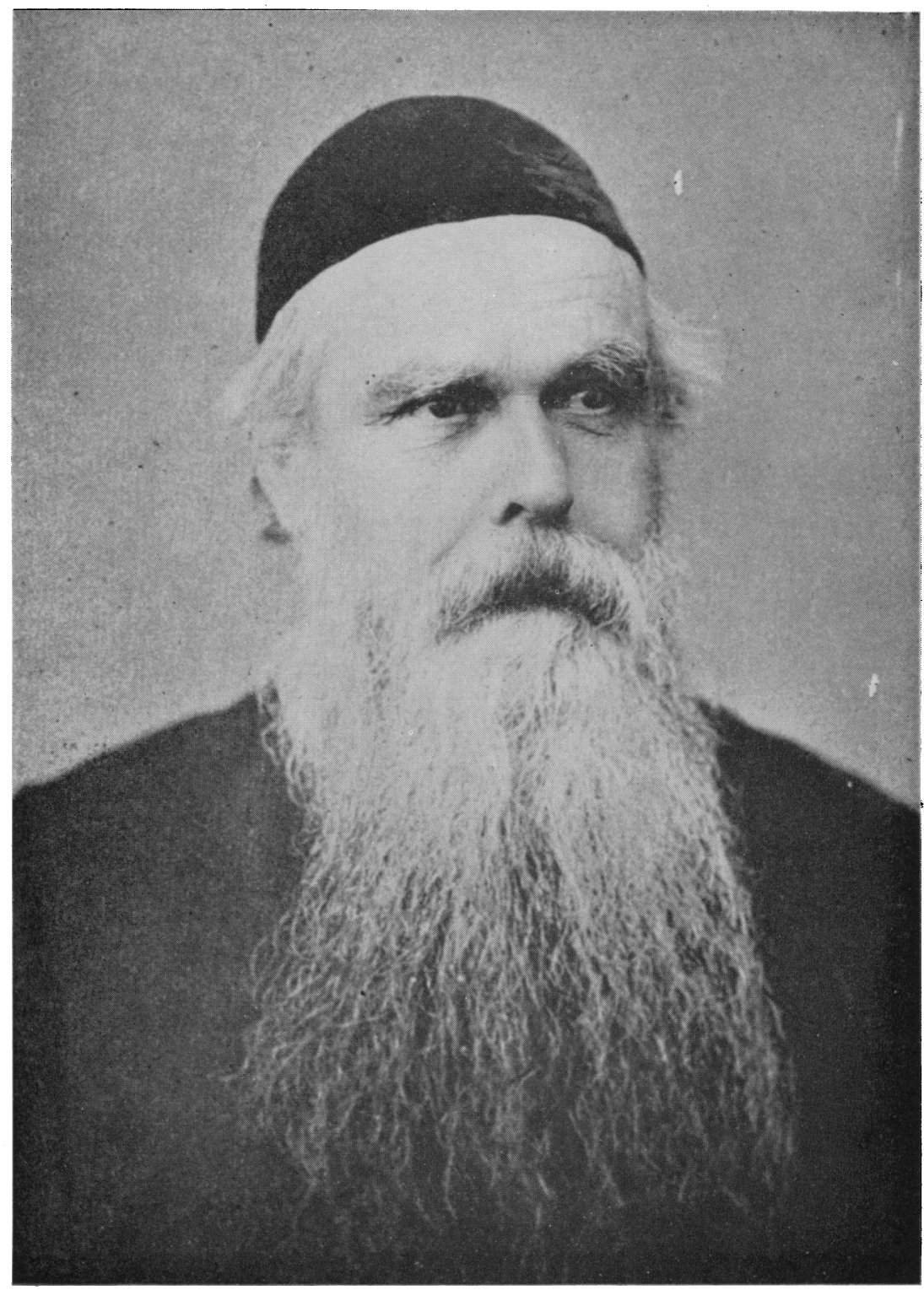

HENRY WHITEHEAD

( I 825-1896)

From a portrait taken in 1884 and reproduced in Henry

Whitehead-A Memorial Sketch, Glasgow, 1898 . 